\title{
The Role of Spiritual Leadership in Reducing Bullying Behavior: A Study on the Industrial Companies in Egypt
}

\author{
Wageeh A. Nafei ${ }^{1}$ \\ ${ }^{1}$ University of Sadat City, Menoufia, Egypt \\ Correspondence: Wageeh A. Nafei, University of Sadat City, Menoufia, Egypt. E-mail: dr.wageeh@yahoo.com
}

Received: November 24, 2017

Accepted: December 15, 2017 Online Published: January 15, 2018

doi:10.5539/ijbm.v13n2p167

URL: https://doi.org/10.5539/ijbm.v13n2p167

\begin{abstract}
The objective of the research is to identify the role of Spiritual Leadership (SL) in reducing Bullying Behavior (BB) at the industrial companies in Egypt. The research community consists of all the employees at the industrial companies (the iron and steel sector, the construction sector, the food industry, the spinning and weaving sector and the chemical industries sector) in Sadat city in Egypt. Due to time and cost constraints, the researcher adopted a sampling method to collect data for the study. The appropriate statistical methods were used to analyze the data and test the hypotheses.

The research has reached a number of results, the most important of which are: (1) the scarcity of research that focused on the study and interpretation of the relation between the study variables (SL and BB) at the industrial companies in Sadat City; (2) SL is a state expressed in a set of organizational dimensions (vision, hope/faith, altruism, meaning/meaning of work, membership, organizational commitment, and productivity), which can be used to reduce the phenomenon of BB; (3) SL is an important tool used by successful managers in developing all employees and spreading social awareness among them; (4) the general average of SL fairly high. The vision as one of the dimensions of SL ranked first, followed by hope and faith, the membership, the organizational commitment, altruistic love, and finally the productivity; (5) the general average of BB is somewhat low. The verbal as one of the dimensions of BB ranked first, followed by physical, property, finally, social BB; (6) there is a statistically significant relationship between the dimensions of SL and BB at the industrial companies in Sadat City.

The research concluded that (1) managers should be interested in the future vision of their units and departments; (2) managers have the element of hope and faith in the vision of the organization; (3) the altruism of leaders in the organization; (4) the conviction of all employees of the organization that the functions they do have significance and meaning both for them and for others; (5) deepening the membership of the organization in all its employees; (6) the attention of managers to raise the level of organizational commitment; (7) the attention of managers to increase productivity and continuous improvement; (8) The design of preventive extension programs in order to reduce $\mathrm{BB}$ as well as its negative effects on both the bully and the victim; (9) the need to pay attention to the provision of job security; (10) taking effective corrective measures to reduce BB in the workplace; (11) attention to reduce $\mathrm{BB}$ in the workplace by avoiding the increase of the functional burden on the staff of the organization, ensuring the safety of the employees, not restricting the freedom and independence of the personnel concerned, the interest in the positive interaction between the employees of the organization, the attention to good relations among individuals or between the employees and their leaders in the organization, and the development of all employees and spreading social awareness among themselves; (12) identifying the psychological aspects associated with the bullying person, taking care of specialized training courses in the field of BB, knowing its causes, how to prevent them, how to deal with it, and transforming it from aggressive behavior to constructive behavior that seeks to adapt and co-operate with others in the organization.
\end{abstract}

Keywords: Spiritual Leadership, Bullying Behavior

\section{Introduction}

There are new concepts in the contemporary administrative business environment. The most important of these is SL (Fry, 2003; Chen \& Yang, 2012). 
Leadership is the art of managing others and generating their desire to achieve common goals (Lean, 2012). Spiritual is a word derived from spirit, which deals with the qualities of the human spirit of love, mercy, patience, forgiveness, satisfaction, and other things that bring happiness to oneself and to others (Fry, 2003).

The spiritual energy of the leader plays an important role in motivating his subordinates on the one hand and his ability to lead these subordinates on the other (Jeon, 2011).

Spirituality is one of the new areas of research (Benefiel et al., 2014). The spiritual individual is the most capable of applying SL, but not necessarily that the individual is spiritually able to exercise SL over his followers (Reave, 2005).

SL is highly popular in education, health care, psychology, as well as in management research. There has been an increase in the number of studies carried out, which shows the interest in SL (Klaus \& Fernando, 2016).

A number of researchers in social research in general and in administrative research in particular have been interested in SL (Giacalone \& Jurkiewic, 2003).

SL plays an important role in improving the level of organizational commitment on the one hand and productivity on the other. This is in addition to their positive impact on the individual, the teams, the building of organizational values, and a sense of community (Jerry, 2009; Chen \& Li, 2013).

SL belongs to the Transformational Leadership School, which focuses on behavior, messages about vision, ambition, emotional feelings, ideological and moral values, attention to individuals, and intellectual motivation of the leader and subordinates (Chen \& $\mathrm{Li}, 2013$ ).

SL plays an important role in creating a positive working environment, new working relationships, and motivating subordinates in a manner that contributes to the organization's goals efficiently and effectively (Polat, 2011).

BB has been of interest to researchers in the study of interpersonal relationships, and perceptions of this behavior have varied (Hodges \& Perry, 1996).

Bullying is an old phenomenon that exists in all societies. The forms of bullying are varied at present, through modern means such as the Internet, e-mails, telephone, or spreading rumors on the Internet and other sites (Dickerson, 2005).

Bullying is acquired from the surrounding environment, which is dangerous for all, one party may exercise psychological and physical harm to another party weak in physical and mental abilities (Beane, 1999).

Interest in BB began in the 1970s and increased interest in it through many studies on BB, which led to the development of preventive guidance programs to reduce this behavior (Olwenus, 2001).

The negative effects of BB are frequent, whether on the bully or the victim, where the parties to bullying suffer from a decline in mental health, loss of self-confidence, and problems in forming a trustworthy friendship (Litz, 2005).

The current study seeks to determine the role of SL in reducing BB at the industrial companies in Sadat city in Egypt.

\section{Spiritual Leadership}

\subsection{Spiritual Leadership Concept}

SL is the use of the leader of his spiritual side as one of the motivational behaviors of his subordinates in a way that helps them discover the moral strength that binds them to others (Lean, 2012).

SL is one of the types of leadership that seeks to satisfy the needs and desires of the employees in the organization by providing psychological needs that help them to continue working in the organization and communicate with others, and belonging to the organization in a way that leads to efficiency in the performance of business, (Chun et al., 2012).

SL is one of the methods that can be followed to improve organizational performance through leaders' attitudes that motivate employees to achieve the goals and vision of their organization (Chen \& Yang, 2012).

$\mathrm{SL}$ is one of the forms of leadership that can be followed by leaders in an organization in a way that achieves its goals efficiently and effectively (Karadag, 2009).

$\mathrm{SL}$ is a set of human values that constitute the working environment of an organization, where its employees demonstrate their abilities and skills (Burkhart, 2008). 
SL is a set of aspects relating to the personality of the individual, which serves as the primary engine of the physical body (Wilson et al., 2008).

SL is a set of positive emotions such as gratitude, forgiveness, and hope that have proven to help individuals engage in behaviors that contribute to productivity and the development of relationships within the organization (Bono \& Mc Cullough, 2006).

SL is a form of leadership and seeks to transform the workplace into a more comfortable and productive place, on the one hand, and providing the needs of employers and employees on the other (Thanakappan, 2005).

SL is a set of values, attitudes, and behaviors necessary to motivate one's self, on the one hand, and to motivate others on the other (Fry, 2003).

SL is a reliable leadership technique in motivating subordinates to achieve high levels of organizational and productive commitment. It is a set of values, attitudes, and behaviors that stimulate one's self and others in order to have a sense of survival in a spiritual life (Fry et al., 2005).

SL is a phenomenon that occurs in the organization when the leader is honest and modest in his actions, and behavior in the organization in a way that reflects his respect for himself and others. It is one of the forms of leadership that can be used to provide the basic needs of employees, on the one hand, and to achieve satisfaction on the other. This is in addition to changing the business philosophy towards the organization from being mutually beneficial with the organization that they are working to achieve their own values (Reave, 2005).

SL is one of the methods of integrating the values, processes and systems of the organization with the values and aspirations of its personnel, in other words creating an atmosphere of harmony between individuals and the organization (Benefiel, 2005).

SL is to teach subordinates the methods that enable them to govern themselves and create the right conditions so subordinates can work freely with their leaders within the organization (Fairholm, 1996).

\subsection{Spiritual Leadership Dimensions}

There are six dimensions of SL (Zavvareh et al., 2013; Polat, 2011). They can be explained as follows:

1). Vision

There must be a clear vision of what the organization would like to be in the future. The term vision was rarely used in leadership literature until the 1980s. At the moment, leaders in business organizations have had to give greater attention to future direction due to the intensity of competition and technological development. Spiritual leaders try to motivate subordinates through a clear vision of the organization.

\section{2). Hope / Faith}

Hope is the desire to expect achievement; faith is beyond hope or expectation of something desirable; faith is more than just a wish for something. It depends on values, attitudes and behaviors that ensure certainty and absolute certainty that what is desired and expected will be achieved. In general, hope and faith are the sources of belief and conviction that the vision and mission of the Organization will be realized.

\section{3). Altruistic Love}

Altruistic love is the sense of integration, harmony, and well-being resulting from the care, attention and appreciation of both self and others. This concept; also, includes the values of patience, compassion, tolerance, humility, altruism, trust, loyalty, and sincerity. In addition, the altruistic love in the SL helps to get rid of destructive feelings such as fear, anger, feeling of failure and others.

\section{4). Meaning/significance of work}

The concept of meaning refers to whether members of the organization believe that the functions they perform are significant and meaningful, and by engaging in work, individuals derive meaning and purpose from life. In addition, individuals who have an internal motivation and drive to learn are finding work, as well as individuals who want to be members of the work group feel they have value and contribution to performance. It is; therefore, clear that meaning and sense of importance are associated with spirituality in the workplace.

\section{5). Membership}

Most individuals tend to work in a group or team, and they prefer to work in an environment in which leaders appreciate their contributions to achieving their goals.

Leaders must therefore be able to create a culture that involves leaders and subordinates interested and responsible for themselves and others. This culture must create a sense of membership. 
SL must therefore take care of the employees in such a way as to create an atmosphere of friendliness and trust among all staff of the organization.

\section{6). Organizational Commitment}

Organizational commitment is one of the main axes of organizational success. SL plays an important role in influencing the level of organizational commitment.

The appropriate leadership styles lead to increased level of job satisfaction for employees. SL also plays an important role in achieving organizational identification and organizational loyalty through organizational commitment and the desire to remain and work in the organization.

\section{7). Productivity}

The availability of the element of hope / faith in the vision of the Organization, their sense of importance and membership makes them do their best to carry out activities that achieve the vision of the organization and thereby increase productivity.

It should be noted that SL plays an important role in increasing the level of job satisfaction, which in turn leads to increased productivity in the organization.

\section{Bullying Behavior}

\subsection{Bullying Behavior Concept}

$\mathrm{BB}$ is the control of an individual or group of individuals over another. This behavior includes verbal development, physical BB, and religious BB in order to isolate the group (Frankova, 2010).

$\mathrm{BB}$ is the repetitive actions and practices of the first party (the bully) to the second party (the victim). These practices are undesirable by the second party (the victim), which can be done intentionally or unconsciously, and cause humiliation and distress to the second party, resulting in an unhealthy working environment, thus affecting the performance of the organization's employees on the one hand and their productivity on the other (Einarsen et al., 2009).

BB is a verbal or nonverbal attack on a person by threatening, intimidating, or humiliating him repeatedly and has negative effects on mental health, loss of self-confidence, and the difficulty of forming a trustworthy friendship (Lutgen-Sandvik et al., 2009).

BB is repeated aggression, whether verbally, psychologically, or physically, and is issued by an individual or group of individuals against others (Smith et al., 2008).

$\mathrm{BB}$ is any behavior resulting from beatings, threats, destruction of property, titles, ridicule and mockery. In other words, BB takes multiple forms, verbal, physical, or symbolic. Verbal bullying occupies the first place as one of the most common forms of BB, followed by symbolic bullying and physical bullying (Gantry, 2001; Yabra \& Wilkens, 2007).

BB is a form of aggressive, unbalanced interaction between two extremes, one called the bully and one called the victim, and takes multiple forms, which may be physical, emotional, or verbal: both direct and indirect (Robyn, 2004; Smorti et al., 2006).

$\mathrm{BB}$ is a state of negative behavior for the purpose of victimization or harassment from a bullying person against another person, the victim, and usually less than the bullying party (Juliffe \& Farrington, 2006).

$\mathrm{BB}$ is an attempt to feel power or desire to control another person, perhaps in the form of verbal bullying, physical bullying, or emotional bullying (Huebner, 2002; Litz, 2005).

BB is a series of negative acts by one or more persons against one or more persons over a long period of time. These negative acts reflect an abusive behavior based on an imbalance in the relationship between the bully and the victim (Sullivan \& Cleary, 2004).

$\mathrm{BB}$ is a deliberate activity intended to cause harm by threatening to attack. This requires an imbalance of power, intent in victimization, threat of aggression, arrogance and contempt (Smith, 2004).

BB is the practice of harming one or more individuals, whether physical, psychological, emotional or verbal, and includes the threat of physical, physical, or other harm (Solberg \& Olweus, 2003).

$\mathrm{BB}$ is the behavior resulting from an imbalance between two extremes, the first called the bully, the other called the victim, and the physical, verbal, or other forms of humiliation (Juvonen et al., 2003). 
$\mathrm{BB}$ is that an individual is subjected to negative behavior from another side, and this behavior results in physical, verbal, emotional or psychological harm, and this behavior is often intentional and deliberate (Wolke et al., 2002).

$\mathrm{BB}$ is a form of aggression, in which there is no balance between the extremities, the bullying and the victim. The bully is often stronger than the victim. Bullying takes many forms that may be verbal, physical, or psychological, and may be direct or indirect, on the victim (Pepler \& Cragi, 2000).

BB is an interaction between two extremes: the first is the bullying person and the second is the victim. This interaction is influenced by the individual characteristics of the parties, the interactive processes among them, and the framework in which the BB emerges (Atlas \& Pepler, 1998).

BB is the negative behavior of a party called the bully and the other called the victim, and in most cases this behavior causes pain to the other party, whether physically or verbally, emotionally, or psychologically. In other words, BB is any aggressive behavior practiced by the individual against another individual, periodically and repeatedly, resulting in verbal or physical harm, whether directly or indirectly (Olweus, 1993).

$\mathrm{BB}$ is a long-term violence by an individual or group of individuals against another individual who can not defend himself, possibly physically or psychologically (Mellor, 1997).

BB is a physical or verbal abuse by the (bullying) side towards the other party (the victim), through any form of doing acts against his will, which has negative psychological effects on the other party, the victim (Gilbert, 1999).

$\mathrm{BB}$ is the repetition of a range of harassment and some direct behaviors, such as reprimands, ridicule, and the threat of beatings of a person known as a bully towards another person known to the victim to control him (Banks, 1997; Rigby, 1999).

In the light of the above, the researcher considers that BB is any kind of physical, verbal or psychological harm caused by bullying towards a weaker person through beatings, bullying or any form of control and humiliation.

In other words, BB is an aggressive behavior that is repeated and issued by a person (bully) towards another (the victim). This behavior is issued in the form of physical, psychological, verbal or non-verbal acts in order to influence the other.

\subsection{Bulling Behavior Dimensions}

The dimensions of BB are a set of behaviors that appear in the workplace. These dimensions are the threat to professional status (reduction of opinion, general professional humiliation, accusation of lack of effort), threat of personal status (naming, insults and intimidation), isolation (Lack of access to opportunities, physical or social isolation, withholding of information), overwork (unjustified pressure, impossible times, unnecessary imbalances), destabilization (lack of credit when due, unintended tasks, (Samnani \& Singh, 2012).

Another is that the dimensions of BB are verbal bullying (ridicule, provocation, inappropriate comments, threats), physical or physical bullying (beatings, violence, slapping, stabbing and other physical abuse) and emotional bullying (spreading malicious rumors about someone) (cybercrime, e-mail or SMS), social bullying (the persecution of a person and excluded in the work of the staff, and usually social bullying in indirect ways) (Smith, 2008; Hertz, 2013).

There is another dimension of bullying. This is family bullying that occurs between family members or the larger family among relatives (Whittled, 2005).

However, Marees \& Peterman (2010) show that the dimensions of BB are behavioral, physical development, verbal $\mathrm{BB}$, social $\mathrm{BB}$, and $\mathrm{BB}$ against property.

\section{Research Model}

The proposed comprehensive conceptual model is presented in Figure (1). The diagram below shows that there is one independent variable for the study of SL.

There is one dependent variable BB. In light of the above discussion, the research model is as shown in the following figure:

The research framework suggests that SL has an impact on BB. SL as measured consisted of vision, hope/faith, altruistic love, meaning/significance of work, membership, commitment, and productivity (Fry \& Matherly, 2006). BB is measured in the terms: physical, verbal, social, and property (Marees \& Peterman, 2010). 


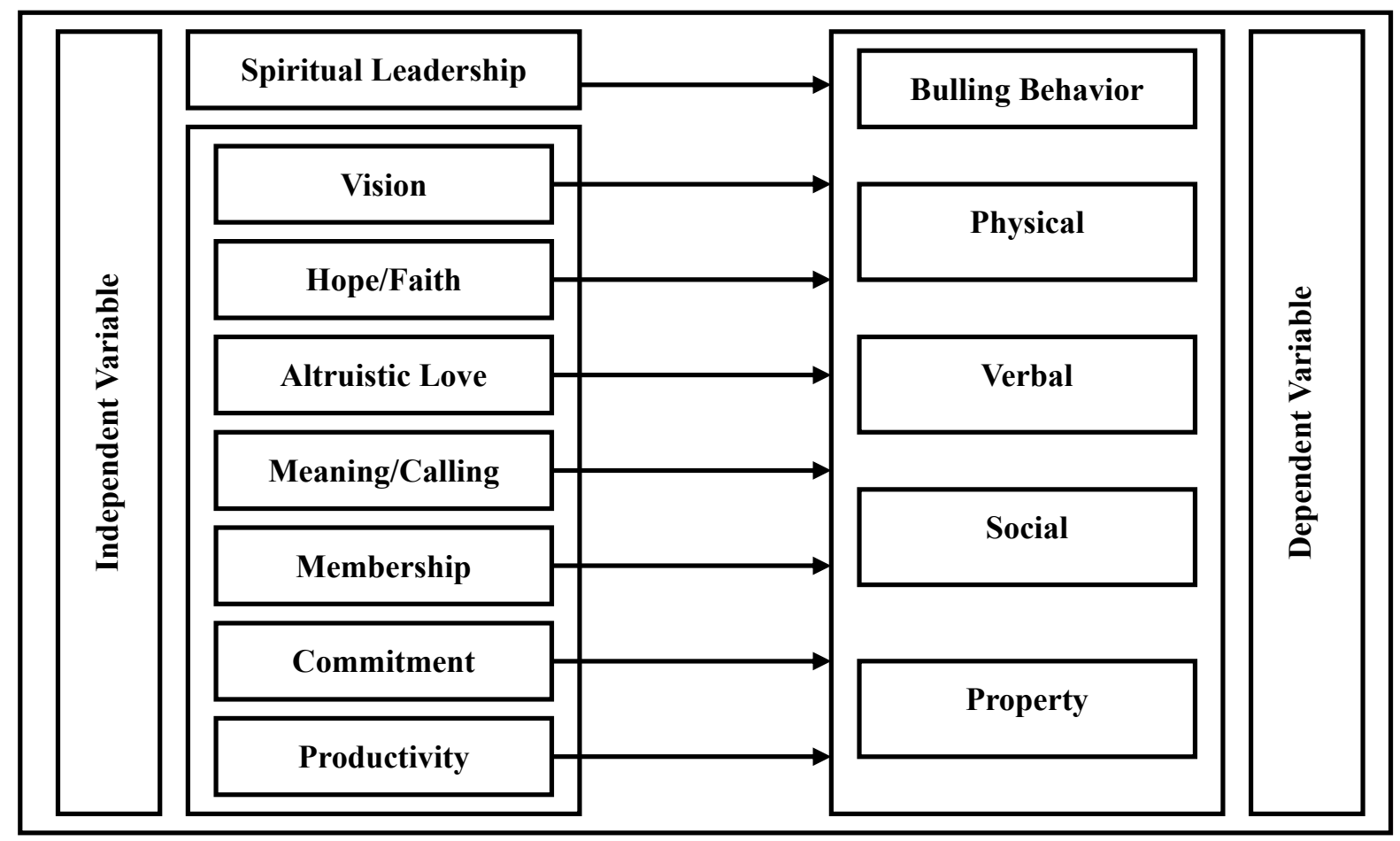

Figure 1. Proposed Comprehensive Conceptual Model

\section{Research Questions}

The researcher reached the research problem through two sources. The first source is to be found in previous studies, and it turns out that there is a lack in the number of literature review that dealt with the analysis of the relationship between SL and BB in the industrial companies in Sadat city in Egypt. This called for the researcher to test this relationship in the Egyptian environment.

In light of the review of previous studies towards SL, literature has shown that there is a significant relationship between SL and organizational commitment, productivity, and satisfaction. SL plays the mediating role in the relationship between job satisfaction, organizational commitment, and productivity (Fry et al., 2017).

SL positively influences the spirituality of the work environment (Afsar et al., 2016). There is also a statistically significant relationship between SL and organizational citizenship behavior (Kaya, 2015).

There is a significant relationship between SL and organizational learning and entrepreneurship (Shafighi et al., 2013).

Another study points out that there is a relationship between SL and job satisfaction (Masouleh et al., 2013). There is a significant relationship between SL and the behavior of organizational citizenship. In other words, SL leads to increased behavior of organizational citizenship (Chen \& Yang, 2012).

The problem of bullying is a serious problem in society. However, there is insufficient attention to this problem in Arab societies, whether in terms of the spread of this problem, or even the diagnostic tools. On the other hand, Western societies have given this problem a great deal of attention in all areas, whether through the media or websites, or awareness campaigns to address this problem (Scarpacia, 2006).

As for $\mathrm{BB}$, literature has shown that $\mathrm{BB}$ is either related to the individual or related to the workplace. People-related bullying is positively associated with work-related depression, while physical intimidation and work-related bullying are positively associated with disorganized behavior (Devonish, 2017).

There is also a statistically significant relationship between BB and job satisfaction as well as intention to leave work. BB negatively affects job satisfaction and intentions of leaving work in the absence of a supportive organizational climate. Both the organizational climate and the cohesion of the task force play the role of the intermediate variable in the relationship between $\mathrm{BB}$ and job satisfaction as well as intention intention to leave work (Nwobia \& Aljohani, 2017). 
There is also a relationship between increased workload and BB. Job insecurity plays the mediating role between increasing workloads and increasing $\mathrm{BB}$. The interaction between increased workloads and job insecurity increases the risk of BB (Spagnoli et al., 2017).

The tasks imposed by leaders positively affect BB by controlling the independence of subordinates and their emotional demands. Leadership can lead to increased BB if the freedom and independence of subordinates is restricted (Tuckey et al., 2017).

There is also a negative relationship between BB and the performance and productivity of employees. BB affects the psychological and physical aspects of employees (Karzyzanowska, 2016).

Finally, another study indicated that there is a statistically significant relationship between the low level of relations and the emergence of $\mathrm{BB}$. The study also indicated a correlation between the parties and the level of BB in the organization (Murray et al., 2010).

The second source is the pilot study, which was conducted an interview with (30) employees at the industrial companies in Egypt to identify the dimensions of SL and BB. The researcher found through the pilot study several indicators notably the blurred important and vital role that could be played by SL in reducing BB at the industrial companies in Egypt. The research questions of this study are as follows:

Q1: What is the relationship between SL (vision) and BB at the industrial companies in Sadat city in Egypt?

Q2: What is the nature of the relationship between (Hope/Faith) and BB at the industrial companies in Sadat city in Egypt?

Q3: What is the extent of the relationship between SL (Altruistic Love) and BB at the industrial companies in Sadat city in Egypt?

Q4: What are the nature and the extent of the relationship between SL (Meaning/Calling) and BB at the industrial companies in Sadat city in Egypt?

Q5: What is the relationship between SL (Membership) and BB at the industrial companies in Sadat city in Egypt?

Q6: What is the nature of the relationship between (Organizational commitment) and BB at the industrial companies in Sadat city in Egypt?

Q7: What is the extent of the relationship between SL (Productivity) and BB at the industrial companies in Sadat city in Egypt?

\section{Research Hypotheses}

In the light of the review of previous studies towards SL, the literature has shown that SL has a significant impact on the spirituality of the work environment. SL has no significant impact on job satisfaction. The spirituality of the work environment has a significant impact on job satisfaction. The spirituality of the work environment does not affect the behavior of employees (Sani et al., 2016).

In addition, there is a statistically significant relationship between SL and organizational performance. SL also has a positive and significant impact on organizational performance (Salehzadeh et al., 2015).

There is also a significant correlation between SL and QWL (Bardmili et al., 2013). There is a positive correlation between SL and the happiness of working individuals (Zavareh et al., 2013).

In addition, there is a statistically significant relationship between SL and the empowerment of employees (Esfahani et al., 2013).

One of the studies found a positive and statistically significant relationship between SL and organizational outcomes such as organizational commitment and productivity. The study also indicated that spiritual well-being plays an important role as an intermediate variable between SL and organizational outcomes (Fry et al., 2017).

Finally, another study indicates that there is a statistically significant relationship between SL and organizational culture. The study also pointed out that attendance as one of the dimensions of SL plays an important role in influencing performance, which is reflected in the organizational culture (Karadag, 2009).

As for $\mathrm{BB}$, literature has shown that four main axes of $\mathrm{BB}$ are the political nature of bullying, ridicule towards informal response, formal procedures that exacerbate the problem, and health insurance (Hodgings et al., 2017).

In addition, another study indicated that the infrastructure supporting ethics plays an important role in promoting ethical behavior among employees and preventing immoral behavior, which reduces the BB (Einarsen et al., 2017). 
There is also a statistically significant relationship between the BB and morale of the employees. There is also a significant relationship between $\mathrm{BB}$ and intentions of leaving work as an organizational result. BB is also influenced by some demographic variables such as gender and age (Tag-Eldeen et al., 2017).

In addition, the leadership style plays an important role in limiting BB. Poor leadership also increases the risk of BB (Nica et al., 2016). One study found that there was a positive relationship between BB and intentions of leaving work. There is also a negative relationship between BB and functional performance (Meta \& Sokmen, 2016). Another study indicated that BB plays the role of the intermediate variable between organizational climate and functional combustion. BB has no direct impact on physical health and mental health. BB indirectly affects employees' health through functionality as an intermediate variable (Giorgi et al., 2016).

There is also a statistically significant relationship between the use of strict discipline procedures and the level of $\mathrm{BB}$, as the use of strict procedures leads to a low level of BB (Greory, 2010).

Finally, another study indicated that there were differences between males and females in the level of BB. Differences in the level of BB favor males and social status plays an important role in predicting BB (Marees \& Peterman, 2010).

The following hypotheses were developed to decide if there is a significant correlation between SL and BB.

H1: There is no relationship between SL (vision) and BB at the industrial companies in Sadat city in Egypt

H2: SL (Hope/Faith) has no significant effect on BB at industrial companies in Sadat city in Egypt.

H3: There is no relationship between SL (Altruistic Love) and BB at the industrial companies in Sadat city in Egypt

H4: SL (Meaning/Calling) has no significant impact on BB at industrial companies in Sadat city in Egypt.

H5: There is no relationship between SL (Membership) and BB at the industrial companies in Sadat city in Egypt H6: SL (Organizational commitment) has no significant influence on BB at industrial companies in Sadat city in Egypt.

H7: There is no relationship between SL (Productivity) and BB at the industrial companies in Sadat city in Egypt

\section{Research Strategy}

\subsection{Population and Sample}

The population of the study included all employees at the industrial companies in Sadat city in Egypt. The total population is 11550 employees. Determination of respondent sample size was calculated using the formula (Daniel, 1999) as follows:

$$
\mathrm{n}=\frac{N \times(Z)^{2} \times P(1-P)}{d^{2}(N-1)+(Z)^{2} \times P(1-P)}
$$

The number of samples obtained by 377 employees at the industrial companies in Sadat city in Egypt is presented in Table 1.

Table 1. Distribution of the sample size

\begin{tabular}{llll}
\hline Industrial Companies & Employees & Percentage & Sample Size \\
\hline 1. Iron and Steel Sector & 8100 & $40 \%$ & $377 \mathrm{X} 40 \%=150$ \\
2. Construction Sector & 5926 & $29 \%$ & $377 \mathrm{X} 29 \%=110$ \\
3. Food Industries Sector & 2087 & $10 \%$ & $377 \mathrm{X} 10 \%=38$ \\
4. Textile Sector & 2520 & $13 \%$ & $377 \mathrm{X} 13 \%=49$ \\
5. Chemical Industries Sector & 1567 & $8 \%$ & $377 \mathrm{X} 8 \%=30$ \\
Total & 20200 & $100 \%$ & $377 \mathrm{X} 100 \%=377$ \\
\hline
\end{tabular}

Source: Personnel Department at Industrial Companies, Sadat City, Egypt, 2017.

\subsection{Procedure}

The goal of this study was to identify the significant role of SL in reducing BB. A survey research method was used to collect data. The questionnaire included three questions, relating to SL, BB, and biographical information of employees at industrial companies in Sadat city in Egypt. 
Data collection took approximately two months. About 377 survey questionnaires were distributed by employing diverse modes of communication, such as in person and post. Multiple follow-ups yielded 300 statistically usable questionnaires. Survey responses were $79 \%$.

Table 2. Characteristics of the sample

\begin{tabular}{|c|c|c|c|}
\hline & & Frequency & Percentage \\
\hline \multirow{3}{*}{ 1-Sex } & Male & 230 & $77 \%$ \\
\hline & Female & 70 & $23 \%$ \\
\hline & Total & 300 & $100 \%$ \\
\hline \multirow{3}{*}{ 2- Marital Status } & Single & 130 & $44 \%$ \\
\hline & Married & 170 & $56 \%$ \\
\hline & Total & 300 & $100 \%$ \\
\hline \multirow{4}{*}{ 3- Age } & Under 30 & 100 & $33 \%$ \\
\hline & From 30 to 45 & 125 & $42 \%$ \\
\hline & Above 45 & 75 & $25 \%$ \\
\hline & Total & 300 & $100 \%$ \\
\hline \multirow{4}{*}{ 4- Educational Level } & Secondary school & 75 & $25 \%$ \\
\hline & University & 175 & $58 \%$ \\
\hline & Post Graduate & 50 & $17 \%$ \\
\hline & Total & 300 & $100 \%$ \\
\hline \multirow{4}{*}{ 5- Period of Experience } & Less than 5 years & 50 & $17 \%$ \\
\hline & From 5 to 10 & 200 & $67 \%$ \\
\hline & More than 10 & 50 & $16 \%$ \\
\hline & Total & 300 & $100 \%$ \\
\hline
\end{tabular}

\subsection{Research Variables and Methods of Measuring}

The 35-item scale SL section is based on Fry and Matherly (2006). There were five items measuring vision, five items measuring hope/faith, seven items measuring altruistic love, four items measuring meaning/significance of work, five items measuring membership, four items measuring commitment, and five items measuring productivity. The 25-item scale BB section is based on Marees \& Peterman, 2010. There were seven items measuring physical, six items measuring verbal, seven items measuring social, and five items measuring property. Responses to all items scales were anchored on a five (5) point Likert scale for each statement which ranges from (5) "full agreement," (4) for "agree," (3) for "neutral," (2) for "disagree," and (1) for "full disagreement."

\subsection{Data Analysis and Testing Hypotheses}

The researcher has employed the following methods: (1) Cronbach's alpha or ACC, (2) The Multiple Discriminant Analysis (MDA), (3) Multiple Regression Analysis (MRA), and (4) F- test and T-test. All these tests are found in SPSS.

\section{Hypotheses Testing}

Before testing the hypotheses and research questions, descriptive statistics was performed to find out means and standard deviations of SL and BB. 
Table 3. Shows the mean and standard deviations of SL and BB

\begin{tabular}{|c|c|c|c|}
\hline Variables & $\begin{array}{c}\text { The } \\
\text { Dimension }\end{array}$ & Mean & Standard Deviation \\
\hline \multirow{8}{*}{ SL } & Vision & 3.36 & 0.635 \\
\hline & Hope/Faith & 3.17 & 0.649 \\
\hline & Altruistic Love & 3.03 & 0.628 \\
\hline & Meaning/Calling & 3.26 & 0.746 \\
\hline & Membership & 3.17 & 0.650 \\
\hline & Organizational Commitment & 3.16 & 0.685 \\
\hline & Productivity & 2.84 & 0.585 \\
\hline & Total Measurement & 3.14 & 0.613 \\
\hline \multirow{5}{*}{$\mathrm{BB}$} & Physical & 1.70 & 0.462 \\
\hline & Verbal & 1.82 & 0.571 \\
\hline & Social & 1.61 & 0.442 \\
\hline & Property & 1.63 & 0.481 \\
\hline & Total Measurement & 1.70 & 0.431 \\
\hline
\end{tabular}

According to Table 3, among the various facets of SL, most of the respondents identified the presence of vision $(M=3.36, S D=0.635)$, hope/faith $(M=3.17, S D=0.649)$, altruistic love $(M=3.03, S D=0.628)$, meaning/significance of work $(M=3.26, S D=0.746)$, membership $(M=3.17, S D=0.650)$, organizational commitment $(M=3.16$, $S D=0.685)$, and productivity $(M=2.84, S D=0.585)$, total $\mathrm{SL}(M=3.14, S D=0.613)$.

The second issue examined was the different facets of BB (physical, verbal, social, and property). Most of the respondents identified the presence of physical $(M=1.70, S D=0.462)$, verbal $(M=1.82, S D=0.571)$, social $(M=1.61$, $S D=0.442)$, and property $(M=1.63, S D=0.481)$, total $\mathrm{BB}(M=1.70, S D=0.431)$.

\subsection{Evaluating Reliability}

Data analysis was conducted. All scales were first subjected to reliability analysis. Cronbach's Alpha was used to assess the reliability of the scales. Item analysis indicated that dropping any item from the scales would not significantly raise the alphas.

Table 4. Reliability of SL and BB

\begin{tabular}{|c|c|c|c|c|}
\hline & $\begin{array}{l}\text { Research } \\
\text { Variables } \\
\end{array}$ & Dimension & $\begin{array}{c}\text { Number of } \\
\text { Statement } \\
\end{array}$ & $\mathrm{ACC}$ \\
\hline \multirow{6}{*}{$\mathrm{SL}$} & & Vision & 5 & 0.684 \\
\hline & & Altruistic Love & 7 & 0.789 \\
\hline & & Meaning/Calling & 4 & 0.745 \\
\hline & & Organizational Commitment & 4 & 0.661 \\
\hline & & Productivity & 5 & 0.610 \\
\hline & & Total Measurement & 35 & 0.959 \\
\hline \multirow{2}{*}{ BB } & & Physical & 7 & 0.737 \\
\hline & & Verbal & 6 & 0.835 \\
\hline
\end{tabular}

To assess the reliability of the data, Cronbach's Alpha test was conducted. Table 4 shows the reliability results for SL and BB. All items had alphas above 0.70 and were therefore excellent, according to Langdridge's (2004) criteria.

Table 4 presents the reliability of SL. The reliabilities of s vision, hope/faith, altruistic love, meaning/significance of work, membership, organizational commitment, and productivity are generally higher. The 35 items of SL are reliable because the Cronbach's Alpha is 0.959 . 
The vision, which consists of 5 items, is reliable because the Cronbach's Alpha is 0.684 . The 5 items related to hope/faith, are reliable because the Cronbach's Alpha is 0.712 while the 7 items of altruistic love are reliable because the Cronbach's Alpha is 0.789 .

The meaning/significance of work which consists of 4 items is reliable because the Cronbach's Alpha is 0.745 . The 5 items related to membership are reliable because the Cronbach's Alpha is 0.770 while the 4 items of organizational commitment are reliable because the Cronbach's Alpha is 0.661 .

Productivity which consists of 5 items is reliable because the Cronbach's Alpha is 0.610 . Thus, the internal consistency of SL can be acceptable.

According to Table 4, the 25 items of BB are reliable because the Cronbach's Alpha is 0.923 . The physical, which consists of 7 items, is reliable because the Cronbach's Alpha is 0.737 .

The 6 items related to verbal are reliable because the Cronbach's Alpha is 0.835 while the 7 items of social are reliable because the Cronbach's Alpha is 0.758 .

Property, which consists of 5 items, is reliable because the Cronbach's Alpha is 0.726. Thus, the internal consistency of BB can be acceptable.

Accordingly, three scales were defined, SL (35 variables), where Cronbach's Alpha represented about 0.959, and BB (25 variables), where Cronbach's Alpha represented 0.923.

8.2 The Means, St. Deviations, and Correlation among Variables

Table 5. Means, Standard Deviations and Intercorrelations among Variables

\begin{tabular}{ccccc}
\hline Variables & Mean & Std. Deviation & SL & BB \\
\hline Spiritual Leadership & 3.147 & 0.613 & 1.000 & \\
Bulling Behavior & 1.702 & 0.431 & 0.130 & 1.000 \\
\hline
\end{tabular}

Table 5 shows correlation coefficients between the research variables, and results indicate the presence of significant correlation between variables (SL, and BB). The level of SL of employees is high (Mean=3.147; $\mathrm{SD}=0.613$ ), while $\mathrm{BB}$ is (Mean=1.702; $\mathrm{SD}=0.431$ ).

\subsection{The Correlation between SL and BB}

The relationship between SL and BB at the industrial companies in Sadat city in Egypt is presented in the following table:

Table 6. Correlation Matrix between SL and BB

\begin{tabular}{|c|c|c|c|c|c|c|c|c|}
\hline Variables & 1 & 2 & 3 & 4 & 5 & 6 & 7 & 8 \\
\hline Vision & 1 & & & & & & & \\
\hline Hope/Faith & $0.889^{* *}$ & 1 & & & & & & \\
\hline Altruistic Love & $0.849^{* *}$ & $0.961^{* *}$ & 1 & & & & & \\
\hline Meaning/Calling & $0.865^{* *}$ & $0.742^{* *}$ & $0.748^{* *}$ & 1 & & & & \\
\hline Membership & $0.848^{* *}$ & $0.960^{* *}$ & $0.967^{* *}$ & $0.773^{* *}$ & 1 & & & \\
\hline Commitment & $0.893^{* *}$ & $0.919^{* *}$ & $0.910^{* * *}$ & $0.917^{* *}$ & $0.926^{* *}$ & 1 & & \\
\hline Productivity & $0.781^{\text {*** }}$ & $0.914^{* *}$ & $0.970^{* *}$ & $0.651^{* *}$ & $0.933^{\text {*** }}$ & $0.820^{* *}$ & 1 & \\
\hline Bulling Behavior & $0.148^{* *}$ & $0.096^{* *}$ & $0.080^{* *}$ & $0.169^{* *}$ & $0.111^{* *}$ & $0.143^{* *}$ & $0.136^{* *}$ & 1 \\
\hline
\end{tabular}

Note. ** Correlation is significant at 0.01 level.

Based on the Table 6, correlation between SL (vision) and BB is 0.148 . For SL (hope/faith) and BB, the value is 0.096 whereas SL (altruistic love) and BB shows correlation value of 0.080 . Also, the correlation between SL (meaning/calling) and BB is 0.169 . For SL (membership) and BB, the value is 0.111 whereas SL (organizational commitment), and BB shows correlation value of 0.143 . Finally, correlation between SL (productivity) and BB is 0.136 . The overall correlation between SL and BB is 0.130 . 


\subsection{Spiritual Leadership (Vision) and BB}

The relationship between SL (Vision) and BB is determined. The first hypothesis to be tested is:

H1: There is no relationship between $S L$ (vision) and BB at the industrial companies in Sadat city in Egypt

Table 7. MRA Results for SL (Vision) and BB

\begin{tabular}{llcc}
\hline \multicolumn{1}{c}{ The Variables of Vision } & Beta & $\mathrm{R}$ & $\mathrm{R}^{2}$ \\
\hline 1. I understand and am committed to my organization's vision. & $0.268^{* *}$ & 0.008 & 0.006 \\
2. My workgroup has a vision statement that brings out the best in me. & $0.781^{* *}$ & 0.804 & 0.646 \\
3. My organization's vision inspires my best performance. & $0.202^{* *}$ & 0.111 & 0.012 \\
4. I have faith in my organization's vision for its employees. & $0.151^{* *}$ & 0.059 & 0.003 \\
5. My organization's vision is clear and compelling to me. & $0.189^{*}$ & 0.087 & 0.007 \\
- $\quad$ MCC & & 0.821 \\
- DC & & 0.674 \\
- Calculated F & & 121.441 \\
- Degree of Freedom & & 5,294 \\
- Indexed F & Level of Significance & 3.01 \\
$* * \mathrm{P}<.01 ; * \mathrm{P}<.05$. & & 0.000 \\
\end{tabular}

As Table 7 proves, the MRA resulted in the R of 0.821 demonstrating that the 5 independent variables of SL (Vision) construe BB significantly. Furthermore, the value of R square, 5 independent variables of SL (Vision) can explain $67 \%$ of the total factors in BB level. Hence, $33 \%$ are explained by the other factors. Therefore, there is enough empirical evidence to reject the null hypothesis.

\subsection{Spiritual Leadership (Hope/Faith) and BB}

The relationship between SL (Hope/Faith) and BB is determined. The second hypothesis to be tested is:

\section{H2: SL (Hope/Faith) has no significant effect on BB at industrial companies in Sadat city in Egypt.}

Table 8. MRA Results for SL (Hope/Faith) and BB

\begin{tabular}{|c|c|c|c|}
\hline The Variables of Hope/Faith & Beta & $\mathrm{R}$ & $\mathrm{R}^{2}$ \\
\hline $\begin{array}{l}\text { 1. I have faith in my organization and I am willing to "do whatever it takes" to } \\
\text { insure that it accomplishes its mission. }\end{array}$ & $0.109^{*}$ & 0.111 & 0.012 \\
\hline $\begin{array}{l}\text { 2. I persevere and exert extra effort to help my organization succeed because I } \\
\text { have faith in what it stands for. }\end{array}$ & $0.800^{* *}$ & 0.804 & 0.646 \\
\hline $\begin{array}{l}\text { 3. I always do my best in my work because I have faith in my organization and its } \\
\text { leaders. }\end{array}$ & 0.021 & 0.115 & 0.013 \\
\hline $\begin{array}{l}\text { 4. I set challenging goals for my work because I have faith in my organization } \\
\text { and want us to succeed. }\end{array}$ & 0.043 & 0.051 & 0.002 \\
\hline $\begin{array}{l}\text { 5. I demonstrate my faith in my organization and its mission by doing everything } \\
\text { I can to help us succeed. }\end{array}$ & $0.067^{*}$ & 0.011 & 0.001 \\
\hline - $\mathrm{MCC}$ & & 0.810 & \\
\hline $\mathrm{DC}$ & & 0.656 & \\
\hline Calculated F & & 122.248 & \\
\hline Degree of Freedom & & 5,294 & \\
\hline - $\quad$ Indexed F & & 3.01 & \\
\hline - $\quad$ Level of Significance & & 0.000 & \\
\hline
\end{tabular}

*** $\mathrm{P}<.01 ; * \mathrm{P}<.05$.

As Table 8 proves, the MRA resulted in the $\mathrm{R}$ of 0.810 . This means that $\mathrm{BB}$ has been significantly explained by the 5 independent variables of SL (Hope/Faith). As a result of the value of $\mathrm{R}^{2}$, the five independent variables of SL (Hope/Faith) justified only 65\% of the total factors in BB level. Hence, 35\% are explained by the other factors. Therefore, there is enough empirical evidence to reject the null hypothesis. 


\subsection{Spiritual Leadership (Altruistic Love) and BB}

The relationship between SL (Altruistic Love) and BB is determined. The third hypothesis to be tested is:

H3: There is no relationship between SL (Altruistic Love) and BB at the industrial companies in Sadat city in Egypt.

Table 9. MRA Results for SL (Altruistic Love) and BB

\begin{tabular}{|c|c|c|c|}
\hline The Variables of Altruistic Love & Beta & $\mathrm{R}$ & $\mathrm{R}^{2}$ \\
\hline 1. My organization really cares about its people. & $0.149^{* *}$ & 0.132 & 0.017 \\
\hline $\begin{array}{l}\text { 2. My organization is kind and considerate toward its employees, and when they are } \\
\text { suffering, wants to do something about it. }\end{array}$ & $0.806^{* *}$ & 0.804 & 0.646 \\
\hline 3. The leaders in my organization "walk the walk" as well as "talk the talk". & $0.145^{* *}$ & 0.111 & 0.012 \\
\hline 4. My organization is trustworthy and loyal to its employees. & 0.001 & 0.051 & 0.002 \\
\hline 5. My organization does not punish honest mistakes. & $0.127^{* *}$ & 0.012 & 0.001 \\
\hline 6. The leaders in my organization are honest and without false pride. & 0.002 & 0.060 & 0.003 \\
\hline 7. The leaders in my organization have the courage to stand up for their people. & 0.010 & 0.115 & 0.013 \\
\hline - $\quad \mathrm{MCC}$ & & 0.827 & \\
\hline - $\quad \mathrm{DC}$ & & 0.684 & \\
\hline - $\quad$ Calculated F & & 90.481 & \\
\hline - $\quad$ Degree of Freedom & & 7,292 & \\
\hline - $\quad$ Indexed F & & 2.63 & \\
\hline - $\quad$ Level of Significance & & 0.000 & \\
\hline
\end{tabular}

As Table 9 proves, the MRA resulted in the $\mathrm{R}$ of 0.83 demonstrating that the 7 independent variables of SL (Altruistic Love) construe BB significantly. Furthermore, the value of R square, 7 independent variables of SL (Altruistic Love) can explain only 68\% of the total factors in BB level. Hence, $32 \%$ are explained by the other factors. Therefore, there is enough empirical evidence to reject the null hypothesis.

\subsection{Spiritual Leadership (Meaning/Calling) and BB}

The relationship between SL (Meaning/Calling) and BB is determined. The fourth hypothesis to be tested is:

H4: SL (Meaning/Calling) has no significant impact on BB at industrial companies in Sadat city in Egypt.

Table 10. MRA Results for SL (Meaning/Calling) and BB

\begin{tabular}{|c|c|c|c|c|}
\hline & The Variables of Meaning/Calling & Beta & $\mathrm{R}$ & $\mathrm{R}^{2}$ \\
\hline 1. & The work I do is very important to me. & 0.112 & 0.050 & 0.002 \\
\hline 2. & My job activities are personally meaningful to me. & $0.785^{* *}$ & 0.804 & 0.646 \\
\hline 3. & The work I do is meaningful to me. & $0.274^{* *}$ & 0.111 & 0.012 \\
\hline 4. & The work I do makes a difference in people's lives. & $0.147^{* *}$ & 0.059 & 0.003 \\
\hline & $\mathrm{MCC}$ & & 0.815 & \\
\hline - & DC & & 0.665 & \\
\hline - & Calculated F & & 146.218 & \\
\hline$\cdot$ & Degree of Freedom & & 4,295 & \\
\hline - & Indexed F & & 3.31 & \\
\hline - & Level of Significance & & 0.000 & \\
\hline
\end{tabular}

As Table 10 proves, the MRA resulted in the $\mathrm{R}$ of 0.81 . This means that BB has been significantly explained by the 4 independent variables of SL (Meaning/Calling).

As a result of the value of $\mathrm{R}^{2}$ the 4 independent variables of SL (Meaning/Calling) justified $66 \%$ of the total factors in BB level. Hence, $34 \%$ are explained by the other factors. Therefore, there is enough empirical evidence to reject the null hypothesis. 


\subsection{Spiritual Leadership (Membership) and BB}

The relationship between SL (Membership) and BB is determined. The fifth hypothesis to be tested is:

H5: There is no relationship between SL (Membership) and BB at the industrial companies in Sadat city in Egypt

Table 11. MRA Results for SL (Membership) and BB

\begin{tabular}{|c|c|c|c|}
\hline The Variables of Membership & Beta & $\mathrm{R}$ & $\mathrm{R}^{2}$ \\
\hline 1. I feel my organization understands my concerns. & $0.161^{* *}$ & 0.111 & 0.012 \\
\hline 2. I feel my organization appreciates me, and my work. & $0.804^{* *}$ & 0.804 & 0.646 \\
\hline 3. I feel highly regarded by my leadership. & 0.021 & 0.051 & 0.002 \\
\hline 4. I feel I am valued as a person in my job. & 0.010 & 0.038 & 0.001 \\
\hline 5. I feel my organization demonstrates respect for me, and my work. & 0.127 & 0.060 & 0.003 \\
\hline - $\quad \mathrm{MCC}$ & & 0.811 & \\
\hline - $\quad \mathrm{DC}$ & & 0.657 & \\
\hline - $\quad$ Calculated F & & 112.704 & \\
\hline - $\quad$ Degree of Freedom & & 5,294 & \\
\hline - $\quad$ Indexed F & & 3.01 & \\
\hline - $\quad$ Level of Significance & & 0.000 & \\
\hline
\end{tabular}

Table 11 proves that there is a relationship between SL (Membership) and BB in significance level of 0,000. Moreover, the value of $\mathrm{R}^{2}$, the 5 independent variables of SL (Membership) can explain $65 \%$ of the total differentiation in BB level.

For the results of a structural analysis of the MRA, the direct effect of SL (Membership) and BB is obtained. Because MCC is 0.81 , it is concluded that there is enough empirical evidence to reject the null hypothesis.

\subsection{Spiritual Leadership (Organizational Commitment) and BB}

The relationship between SL (Organizational Commitment) and BB is determined. The sixth hypothesis to be tested is:

H6: SL (Organizational commitment) has no significant influence on OP at industrial companies in Sadat city in Egypt.

Table 12. MRA Results for SL (Organizational Commitment) and BB

\begin{tabular}{|c|c|c|c|}
\hline The Variables of Organizational Commitment & Beta & $\mathrm{R}$ & $\mathrm{R}^{2}$ \\
\hline 1. I do not feel like "part of the family" in this organization. & $0.157^{*}$ & 0.050 & 0.002 \\
\hline 2. I would be very happy to spend the rest of my career with this organization. & $0.797^{* *}$ & 0.804 & 0.646 \\
\hline 3. I talk up this organization to my friends as a great place to work for. & $0.248^{* *}$ & 0.111 & 0.012 \\
\hline 4. I really feel as if my organization's problems are my own. & 0.069 & 0.051 & 0.002 \\
\hline - $\quad \mathrm{MCC}$ & & 0.810 & \\
\hline - $\quad \mathrm{DC}$ & & 0.657 & \\
\hline - $\quad$ Calculated F & & 141.186 & \\
\hline - $\quad$ Degree of Freedom & & 4,295 & \\
\hline - $\quad$ Indexed F & & 3.31 & \\
\hline - $\quad$ Level of Significance & & 0.000 & \\
\hline
\end{tabular}

As Table 12 proves, the MRA resulted in the R of 0.81 . BB has been significantly explained by the 4 variables of SL (Organizational Commitment). As a result of the value of $\mathrm{R}^{2}$, the 4 independent variables of SL (Organizational Commitment) justified $65 \%$ of BB. Hence, $35 \%$ are explained by the other factors. Therefore, there is enough empirical evidence to reject the null hypothesis. 


\subsection{Spiritual Leadership (Productivity) and BB}

The relationship between SL (Productivity) and BB is determined. The seventh hypothesis to be tested is:

\section{H7: There is no relationship between SL (Productivity) and BB at the industrial companies in Sadat city in Egypt}

Table 13. MRA Results for SL (Productivity) and BB

\begin{tabular}{|c|c|c|c|}
\hline The Variables of Productivity & Beta & $\mathrm{R}$ & $\mathrm{R}^{2}$ \\
\hline 1. Everyone is busy in my department/grade; there is little idle time. & $0.135^{* *}$ & 0.132 & 0.017 \\
\hline 2. In my department, work quality is a high priority for all employees. & $0.852^{* *}$ & 0.533 & 0.284 \\
\hline 3. In my department, everyone gives his/her best efforts. & $1.11^{* *}$ & 0.012 & 0.001 \\
\hline 4. My work group is very productive. & $1.11^{* *}$ & 0.060 & 0.003 \\
\hline $\begin{array}{l}\text { 5. My work group is very efficient in getting maximum, output from the resources } \\
\text { (money, people, equipment, etc.) we have available }\end{array}$ & 0.075 & 0.115 & 0.013 \\
\hline - $\quad \mathrm{MCC}$ & & 0.749 & \\
\hline - $\quad \mathrm{DC}$ & & 0.562 & \\
\hline - $\quad$ Calculated F & & 75.357 & \\
\hline - $\quad$ Degree of Freedom & & 5,294 & \\
\hline - $\quad$ Indexed $\mathrm{F}$ & & 3.01 & \\
\hline - Level of Significance & & 0.000 & \\
\hline
\end{tabular}

$* * \mathrm{P}<.01$

Table 13 proves that there is a relationship between SL (Productivity) and BB. As a result of the value of $\mathrm{R}^{2}$, the 5 independent variables of SL (Productivity) can explain 56\% of the total differentiation in BB level. For the results of a structural analysis of the MRA, the direct effect of SL (Productivity) and BB is obtained. Because MCC is 0.75 , there is enough empirical evidence to reject the null hypothesis.

\section{Research Results}

By reviewing the results of descriptive analysis of the data on which the study was based and testing the research hypothesis, the study reached a set of results which will be reviewed and discussed as follows:

1. The scarcity of research that focused on the study and interpretation of the relation between the study variables (SL and BB) in the Egyptian business environment in general and industrial companies in Sadat City in particular.

2. SL is a state expressed in a set of organizational dimensions: vision, hope/faith, altruism, meaning/meaning of work, membership, organizational commitment, and productivity, which can be used to reduce the phenomenon of $\mathrm{BB}$ in productive organizations and service.

3. SL is an important tool used by successful managers in developing all employees and spreading social awareness among them in such a way as to enable them to deal with BB within the work environment by avoiding increasing functional burdens, providing job security, freedom and independence of employees, and positive interaction between employees and good relations among themselves.

4. The general average of SL at the industrial companies in Sadat city in Egypt is fairly high. The vision as one of the dimensions of SL ranked first, followed by the concerned or the second, the hope and faith in the third place, the membership in the fourth place, the organizational commitment in the fifth place, the altruistic love ranked sixth, and finally the productivity as one of the dimensions of SL at the industrial companies in Sadat city in Egypt.

5. The general average of the behavior of development at the industrial companies in Sadat city in Egypt is somewhat low. Behavior was followed by verbal physical development, followed by physical development in second place, physical development versus property in third place, and social BB in fourth place as a dimension of $\mathrm{BB}$ at the industrial companies in Sadat city in Egypt.

6. There is a statistically significant relationship between the dimensions of SL (vision, hope/faith, altruism, meaning/significance of work, membership, organizational commitment, productivity) and the dimensions of BB (physical, verbal, social, and property). The industrial city of Sadat is taken in aggregate, and each dimension of SL is studied separately. 


\section{Recommendations}

In the light of the previous results, the researcher concluded with a set of recommendations. These recommendations can be summarized as follows:

1. The need for managers' attention to the future vision of their units and departments, with realistic vision and the possibility of implementation with the highest degree of efficiency and effectiveness. This can be done through the involvement of staff in their development, which entails the effort and strive to achieve.

2. The need for managers to have the element of hope and faith in the vision of the Organization, since they are the source of belief and conviction that the vision and mission of the Organization will be achieved, and can be done through material rewards on the one hand, and involvement in their development on the other.

3. The need to have the altruistic love among the leaders in the organization, or in other words the need to have a sense of integration and attention and appreciation for both self and others, and can be done by teaching managers the values of patience, honesty. This will lead to a sense of employees, i.e. the altruistic love. In addition, the altruistic love among managers will help to eliminate destructive feelings such as fear, anger, feelings of failure, and false pride.

4. The need for all employees of the organization to be convinced that their jobs are important and meaningful both for themselves and for others. Work has a social meaning and adds value to them, and work helps them to serve others and thus derive a purpose and meaning in life.

5. The need to deepen the membership of the organization in all its employees, since the sense of employees belonging to a particular organization creates an atmosphere of friendliness and trust among employees and leaders, creating the sense of membership and recognition.

6. The need for managers to raise the level of organizational commitment, as appropriate leadership methods lead to increased job satisfaction among employees, which in turn raises the level of organizational commitment to them. In addition, the sense of belonging to the organization will create a sense of loyalty to the organization and would like to remain in it, since the culture of the organization is based on altruism, which raises the level of organizational commitment.

7. The need for managers to increase productivity and continuous improvement, as the availability of hope and faith in the vision of the Organization, their sense of importance, and membership will do their utmost to achieve the vision and mission of the Organization, and work on improvement and continuous development, which leads to increased productivity. In addition, following the method of SL will contribute mainly to increasing the productivity of the organization. In other words, it is necessary to take care of spirituality in the workplace through SL, which leads to a sense of quality of work environment, thus increasing the level of job satisfaction, organizational commitment and thus increasing productivity.

8. The need for managers to have the basic qualifications of leadership, which includes vision, faith and hope, in addition to the need to harmonize the organization's practices and objectives in order to create an atmosphere of spirituality in the workplace and to achieve a more efficient and effective environment.

9. The need to design preventive extension programs in order to reduce $\mathrm{BB}$ as well as the negative consequences of it, either on the bully or on the victim. This can be done through specialized training programs for managers, as training plays an important role in increasing leaders' knowledge of how to deal with and reduce BB in the workplace.

10. The need to pay attention to the provision of job security, and this can be done through the management practices and leadership of managers in a manner that works to reduce the phenomenon of $\mathrm{BB}$, which leads to improving the performance of workers on the one hand, and reduces the intentions to leave work on the other hand.

11. The need to take effective corrective measures to reduce the BB through the need to respond to the demands of employees and listen to their complaints, and trying to solve the problems facing them. This leads to the creation of a healthy and safe environment in the organization, performance and productivity of employees.

12. To identify the psychological aspects associated with the bullying person, which requires the need to conduct training programs to reduce $\mathrm{BB}$ in any form, as well as raising awareness and leadership development on how to deal with BB.

13. Increase the awareness of leaders in the organization of the causes of $B B$ through specialized training courses in the field of BB, and know the reasons, and how to prevent as well as how to deal with them, and conversion from aggressive behavior to constructive behavior seeks to adapt and cooperate with others in the organization. 
14. Increasing the awareness of leaders in the organization of the causes of bullying through specialized training courses in the field of BB, and knowing the reasons, how to prevent them, and how to deal with it, and conversion from aggressive behavior to constructive behavior seeks to adapt and cooperate with others in the organization.

15. The need to pay attention to work to reduce the phenomenon of BB and can be done through:

- Avoiding increasing the functional burden on the staff of the organization.

- The need to provide a great deal of job security for the employees of the organization.

- Not restricting the freedom and independence of individuals working in the organization.

- Pay attention to the process of positive interaction among individuals working in the organization.

- Pay attention to good relations between employees among themselves or between employees and their leaders in the organization.

- The need to develop all employees and to spread social awareness among them in a way that makes them able to deal with BB within the work environment.

\section{Future Research Proposals}

The current research sought to reveal the role of SL in reducing the behavior of development at the industrial companies in Sadat city in Egypt.

However, the scope of this research and the methods used in the results and indicate the existence of areas for future studies that are no less important in this regard. These include: (1) the role of SL in achieving organizational excellence; (2) the role of SL in attaining organizational identification; (3) the role of SL in promoting organizational success; and (4) evaluation of BB in Egyptian universities.

\section{References}

Afsar, B., Badir, Y., \& Kian, U. (2016). Linking spiritual leadership and employee pro-environmental behavior: The influence of workplace spirituality, intrinsic motivation, and environmental passion. Journal of Environment Psychology, 45, 79-88.

Atlas, R., \& Pepler, D., (1998). Observations of Bullying in the Classroom. Journal of Education, 92, 86-99.

Banks, R. (1997). Bullying in Schools. ERIC Digest, Washington, DC : U. S. Department of Education and Justice.

Bardmili, S. H., Siadat, S. A., \& Mohammadisadr, M. (2013). The Study of Relation between Spiritual Leadership of Principals and Quality of Work Life of Teachers in High Schools of City of Izehajati. International Journal of Scientific and Research Publications, 3(7), 1-4.

Beane, A. (1999). The Bully Free Classroom: Over 100 Tips and Strategies for Teachers K - 8. (Minneapolis: Free Sprit Publishing).

Benefiel, M. (2005). The second half of the journey: Spiritual leadership for organizational transformation.

Benefiel, M., Fry, L. W., \& Giegle, D. (2014). Spirituality and religion in the workplace: History, theory, and research. Psychology of Religion and Spirituality, 6(3), 175-187. http://dx.doi.org/10.1037/a0036597

Bono, G., \& McCullough, M. (2006). Positive Responses to Benefit and Harm: Bringing Forgiveness and Gratitude Into Cognitive Psychotherapy. Journal of Cognitive Psychotherapy, 20(2), 147-158.

Burkhart, L. (2008). Addressing Spiritual Leadership: An Organizational Model. Journal of Nursing Administration, 38(1), 33-39.

Chen, C., \& Li, C. (2013). Assessing the spiritual leadership effectiveness: The contribution of follower's self-concept and preliminary tests for moderation of culture and managerial position.

Chen, C., \& Yang, C. (2012). The Impact of Spiritual Leadership on Organizational Citizenship Behavior: A Multi-Sample Analysis. Journal of Business Ethics, 105(1), PP.107-114.

Chun, C., \& Chin, Y, (2012). Spiritual Leadership, Follower Mediators, and Organizational Outcomes: Evidence From Three Industries Across Two Major Chinese Societies. Journal of Applied Social Psychology, 42(4), 890-938.

Devonish, D. (2017). Dangers of workplace bullying: evidence from the Caribbean. Journal of Aggression, Conflict and Peace Research, 9(1), 69-80. https://doi.org/10.1108/JACPR-05-2016-0228

Dickerson, D. (2005). Cyber Bullies on Camps. Retrieved October 5 2006, from the htt://www.unicef.org.violence Einarsen, K., Mykletun, R. J., Einarsen, S. V., Skogstad, A., \& Salin, D. (2017). Ethical Infrastructure and 
Successful Handling of Workplace Bullying. Nordic Journal of Working Life Studies, 7(1), 37.

Einarsen, S., Hoel, H., \& Notelaers, G. (2009). Measuring Exposure to Bulling and Harassment at Work: Validity, Factor Structure and Psychometric Properties of the Negative Acts Questionnaire-Revised. Work and Stress, 23(1), 24-44.

Esfahani, A. N., \& Ghoreyshian, S. A. (2013). The Role of Spiritual Leadership in the Empowerment of Personnel. Journal of Engineering Research and Applications, 3(5), 1257-1274.

Fairholm, G. (1996). Spiritual leadership: fulfilling whole-self needs at work. Leadership \& Organization Development Journal, 17(5), 1-17.

Frankova, L. (2010) School Bullying From the View Point of Moral Cognition Overview of Selected Findings Ceskosllovenska. Psychological, 2, 175-189.

Fry, L. (2003). Toward a theory of spiritual leadership. The Leadership Quarterly, 14, 693-727.

Fry, L. W., Latham, J. R., Clinebell, S. K., \& Krahnke, K. (2017). Spiritual leadership as a model for performance excellence: a study of Baldrige award recipients. Journal of Management, Spirituality \& Religion,14(1), $22-47$.

Fry, L. W., Vitucci, S., \& Cedillo, M. (2005). Spiritual leadership and army transformation: Theory, measurement, and establishing a baseline. The Leadership Quarterly, 16, 835-862.

Fry, L., \& Matherly, L. (2006a), Spiritual Leadership and Organizational Performance. Paper Presented at the Academy of Management, Atlanta, Georgia.

Fry, L., \& Matherly, L. (2006b), Spiritual Leadership as an Integrating Paradigm for Positive Leadership Development. Paper Presented at the International Gallup Leadership Summit, Washington, DC.

Gentry, J. (2001). Understanding Child Development as a Violence Prevention. American Psychological Association, 5(20), 14- 26.

Giacalone, R., \& Jurkiewic, C. (2003). Handbook of Workplace Spirituality and Organizational Performance (3rd ed.). New York.

Gilbert, S. (1999) Study Finds Bullies and Victims are More Alike Than Different Both Group likely to be Suffering from Depression. Retrieved October 5, 2006, from http://www.sfGate.com

Giorgi, G., Mancuso, S., Fiz Perez, F., Castiello D'Antonio, A., Mucci, N., Cupelli, V., \& Arcangeli, G. (2016). Bullying among nurses and its relationship with burnout and organizational climate. International Journal of Nursing Practice, 22(2), 160-168.

Greory, A., Carnell, D., Fan, X., Shears, P., \& Huang. F. (2010) Authoritative School Discipline High School Practices Associated With Lower Bullying. Journal of Education Psychology, 102(2), 483- 496.

Hertz, M., \& Donato, I. (2013). Bullying and Suicide: A Public Health Approach. Journal of Adolescent Health, 53, 51-53.

Hodges, T., \& Perry, D. (1996). Victims of peer abuse: An overview. Journal of Emotional and Behavioral Problems, 5(I), 25-29.

Hodgins, M., \& McNamara, P. (2017). Bullying and incivility in higher education workplaces: Micro politics and the abuse of power. Qualitative Research in Organizations and Management: An International Journal, 12(3), 190-206.

Huebner, A. (2002). Adolescent Bullying. Human Development. Posted April2002.http://www.ext.vt.edu/pubs/family/350-852/350-52.html.

Jeon, K. S. (2011). The Relationship Of Perception Of Organization Performance and Spiritual Leadership, Workplace Spirituality, And Learning Organization Culture In The Korean Context, PhD dissertation, The Graduate School, The Pennsylvania State University, USA.

Jerry, J. (2009). The Leadership Quarterly special issue on Spiritual Leadership. The Leadership Quarterly, 29(4), 491-492.

Joliffe, D., \& Farrington, D. (2006). Examining the Relationship Between Low Empathy and Bullying. Aggressive Behavior, 4(32), 540-550.

Juvonen, J., Graham, S., \& Shuster, M. (2003). Bullying Among Young Adolescent: The Strong, The Weak, and The Troubled. Pediatrics, 112(6), 1231-1238. Retrieved October 5, 2006, from EBSCO host Master File data 
base.

Karadag, E. (2009). Spiritual Leadership and Organizational Culture: A Study of Structural Equation Modeling. Educational Sciences: Theory and Practice, 9(3), 1391-1405.

Kaya, A. (2015). The Relationship between Spiritual Leadership and Organizational Citizenship Behaviors: A Research on School Principals' Behaviors. Educational Sciences: Theory \& Practice, 15(3), 597-606.

Klaus, L., \& Fernando, M. (2016). Enacting spiritual leadership in business through ego-transcendence. Leadership \& Organization Development Journal, 37(1), 71-92.

Lean, E. R. (2012). The Construct Development of Spiritual Leadership. PhD dissertation, University of Arkansas, SA.

Litz, E. (2005). An Analysis of Bullying Behaviors at E. B. Stanley Middle School in Abingdon, Virginia. Published doctoral Dissertation, East Tennessee State University.

Marees, N., \& Peterman, F., (2010) Bullying in German Primary school :Gender Differences ,Age Treds and Influence of Parents Migration and Educational Background School. Psychology International, 31(2), $178-198$.

Masouleh, A., Koochaksaraei, M., Saeedi, N., \& Mousavian, I. (2013), Studying the relationship between spiritual leadership and job satisfaction. Elixir Human Resource Management, 56, 3476-13480.

Mellor, A. (1997). Bullying in Scottish Secondary Schools.

Mete, E. S., \& Sökmen, A. (2016). The Influence of Workplace Bullying on Employee's Job Performance, Job Satisfaction and Turnover Intention in a Newly Established Private Hospital. International Review of Management and Business Research, 5(1), 65-79.

Murray, S., Harvvey. P., \& Slee, P., (2010). School And Home And There Impact on School Bullying School. Psychology International, 31(3), 271-295.

Nica, E, Hurjui, I., \& Stefan, I. (2016). The Relevance of the Organizational Environment in Workplace Bullying Processes. Journal of Self-Governance and Management Economics, 4(2), 83-89.

Nwobia, I. E., \& Aljohani, M. S. (2017). The Effect of Job Dissatisfaction and Workplace Bullying on Turnover Intention: Organization Climate and Group Cohesion as Moderators. International Journal of Marketing Studies, 9(3), 136-143.

Olweus, D. (1993). Bullying at School: What We Know and What We Can Do? Cambridge, MA: Black Well Publishers.

Olweus, D. (2001). Bullying at School, Tackling the Problem, Research Center for Health Promotion. Retrieved from http://www.Oecdobserve.Org/news/fullstory.Php/aid/434/bullying at school. Tackling the problem.html

Pepler, D., \& Craig, W. (2000). Making a difference in bullying. New York: La Marsh Center for Research on violence and conflict Resolutions.

Polat, S. (2011). The Level of Faculty Members' Spiritual Leadership (SL) Qualities Display According To Students in Faculty of Education. Procedia - Social and Behavioral Sciences, 15, 2033-2041.

Reave, L. (2005). Spiritual values and practices related to leadership effectiveness. The Leadership Quarterly, 16(5), 655-687.

Rigby, K. (1999). Bullying among Australian School children. The Canadian Journal of Psychiatry, 44(9), $463-575$

Robyn, C. (2004). SMS bullying, (Bullying \& Violence). Youth Studies Australia, 23(2), 3-5.

Salehzadeh, R., Pool, J., Lashaki, J., Dolati, H., \& Jamkhaneh, H. (2015). Studying the effect of spiritual leadership on organizational performance: an empirical study in hotel industry. International Journal of Culture, Tourism and Hospitality Research, 9(3), 346-359.

Samnani A. K., \& Singh P. (2012). 20 Years of workplace bullying research: a review of the antecedents and consequences of bullying in the workplace. Aggress. Violent Behav, 17, 581-589. https://doi.org/10.1016/j.avb.2012.08.004

Sani, A., Soetjipto, B. E., \& Maharani, V. (2016). The Effect of Spiritual Leadership on Workplace Spirituality, Job Satisfaction and Ihsan Behaviour (A Study on Nurses of Aisyiah Islamic Hospital in Malang, Indonesia). International Journal of Applied Business and Economic Research, 14(11), 7675-7688. 
Scarpacia, R. (2006). Bullying: Effective strategies for its prevention. Kappa Delta Pi Record: Finsburg Printing.

Shafighi, F., Ajili, G. Z., \& Ajili, Gholamhosein, A. (2013), Relationship between the Spiritual Leadership and Organizational Entrepreneurship with Regard to the Mediating Role of Organizational Learning. Journal of Applied Environmental and Biological Sciences, 3(6), 21-30.

Smith, C. (2004). Raising Courageous Kids: Bullying Facts. Extension Specialist in Kansas State University Research and Extension.

Smith, P., Smith, C., Osborn, R., \& Samara, M. (2008). A content analysis of school anti-bullying policies: Progress and limitations. Educational psychology in Practice, 24(1), 1-12.

Smorti, A., Ortega, J., \& Ortega, R. (2006). Discrepant Story Task: An instrument used to explore narrative strategies in bullying. Electronic Journal of Research in Educational Psychology, 9(2), 397-426.

Solberg, M., \& Olweus, D. (2003). Prevalence Estimation of School Bullying with the Olweus Bully/Victim (9) Questionnaire. Aggressive Behavior, 29, 239-268.

Spagnoli, P., Spagnoli, P., Balducci, C., \& Balducci, C. (2017). Do high workload and job insecurity predict workplace bullying after organizational change? International Journal of Workplace Health Management, $10(1), 2-12$.

Sullivan, K., \& Cleary, M. (2004). Bullying in Secondary Schools: What it looks like aiitl How to Manage it? New York: Sage Publishing.

Tag-Eldeen, A., Barakat, M., \& Dar, H. (2017). Investigating the Impact of Workplace Bullying on Employees' Morale, Performance and Turnover Intentions in Five-star Egyptian Hotel Operations. Tourism and Travelling Journal, 1(1), 4-14.

Thankappan, S. (2005). The Role of Spiritual Leadership in Meeting the Organizational Challenges of the 21st Century. PhD dissertation, School of Management, Walden University, USA .

Tuckey, M., Yiqiong, Li, \& Peter, Y. C. (2017). The role of transformational leadership in workplace bullying: Interactions with leaders' and followers' job characteristics in a multi-level study. Journal of Organizational Effectiveness: People and Performance, 4(3), 199-217. https://doi.org/10.1108/JOEPP-01-2017-0008

Whitted, K. (2005). Student Reports of Physical and Psychological Maltreatment in Schools: An under-Explored Aspect of Student Victimization in Schools.

Wilson, C. L. (2009). A Relational Study of Leadership Spiritually and Organizational Performance in Home Health Care Agencies, PhD, dissertation, University of Phoenix, USA.

Wolke, D, Sarah, W, Stanford, K., \& Schulzs (2002). Bullying and Victimization of Primary School Children in England and German: Prevalence and School Factors. British Journal of Psychology, 92, 673-696.

Yabrra, G., \& Wilkens, S. (2007) .The Influence of Domestic Violence on the Preschooler Behavior and Functioning.

Zavareha, F., Hanaeinezhadb, Z., \& Aboofazelib, M. (2013). An Investigation on Effects of Spiritual Leadership towards Employee's Happiness Using Structural Equation Modeling. International Journal of Management Academy, 1(1), 1-8.

\section{Copyrights}

Copyright for this article is retained by the author(s), with first publication rights granted to the journal.

This is an open-access article distributed under the terms and conditions of the Creative Commons Attribution license (http://creativecommons.org/licenses/by/4.0/). 